\title{
SENI KERAJINAN KELOM GEULIS DI KOTA TASIKMALAYA SEBAGAI PELENGKAP FASHION WANITA
}

\author{
Agus Nero Sofyan, Kunto Sofianto, Maman Sutirman, dan Dadang Suganda \\ Fakultas Ilmu Budaya Universitas Padjadjaran \\ E-mail: agus.nero@unpad.ac.id
}

\begin{abstract}
ABSTRAK. Penelitian ini berjudul "Seni Kerajinan Kelom Geulis di Tasikmalaya sebagai Pelengkap Fashion Wanita". Tasikmalaya merupakan kawasan di Priangan Timur Provinsi Jawa Barat. Penelitian ini mengkaji pemerolehan dan pemilihan bahan baku, proses produksi (desain, pengukuran, pencetakan, pengepakan, dan pelabelan), dan pemasaran. Metode penelitian yang digunakan adalah metode deskriptif-analitik. Teknik pengumpulan data dalam penelitian ini adalah survei ke lapangan melalui wawancara, pengamatan secara langsung, dan pengambilan sumber-sumber tertulis dari masyarakat dan pemerintah setempat. Selain itu, teknik pengumpulan data dilakukan dengan cara pengambilan gambar di lapangan. Tujuan penelitian ini adalah untuk mengkaji kelom geulis sebagai pelengkap fashion wanita. Kelom geulis adalah jenis kerajinan khas yang berasal dari Tasikmalaya yang dibuat turun-temurun. Kelom geulis bagian dari jenis sandal pada umumnya. Sumber data yang digunakan dalam penelitian ini adalah data lapangan melalui participant observation sebagai data primer dan sumber kepustakan sebagai data sekunder. Objek penelitian ini adalah kelom geulis di Tasikmalaya. Masalah yang dibahas dalam penelitian ini adalah bagaimana pemerolehan dan pemilihan bahan baku kelom yang berkualitas, proses produksi mulai dari mendesain, mengukur, mencetak, melabel, dan mengepak, serta memasarkan kelom geulis ke tempat-tempat yang strategis, baik dalam maupun luar negeri. Hasil yang dicapai dari penelitian ini bahwa kelom geulis produksi Kota Tasikmalaya memiliki kualitas yang baik, meningkatkan fashion pemakainya sehingga nyaman dipandang (eye-cathcing), dan meningkatkan jumlah produksi karena banyak permintaan dari dalam dan luar negeri. Selain itu, usaha pemerintah setempat dalam pelestarian seni produksi kelom geulis dengan memberikan peningkatan modal kepada para perajin, mendatangkan investor, dan memberikan peluang pemasaran baik di dalam maupun di luar.
\end{abstract}

Kata kunci: seni kelom geulis, Tasikmalaya, fashion, wanita, pemasaran

\section{ART OF KELOM GEULIS HANDICRAFTS IN TASIKMALAYA CITY AS COMPLEMENTARY OF WOMEN'S FASHION}

\begin{abstract}
The title of this research is Art of Kelom Geulis Handicrafts in Tasikmalaya as Complementary of Women's Fashion. Tasikmalaya is an area in East Priangan West Java Province. In this research, will be studied the acquisition and selection of raw materials, production processes and marketing. The method used in this research is descriptive-analytic method, that describes the phenomena of the existence which took place nowadays or the past. Data collection techniques in this research is field surveys through interviews, direct observation, and the retrieval of written sources from local communities and government. In addition, data collection techniques are conducted by taking pictures in the field. The study purpose is to study the kelom geulis as a complement of women's fashion. Kelom geulis is a type of typical craft coming from Tasikmalay a made by hereditary. Kelom geulis is part of the type of sandals in general. Data sources used in this research is field data through participant observation as primary data and source of lust as secondary data. The research object is a kelom geulis Tasikmalaya. The results achieved from this research is the production of Tasikmalaya City has good quality, improves the fashion of the wearer so that it is comfortable eye-cathcing, and increases the number of production due to the many requests from home and abroad. The local government's efforts in the preservation of the art of production of kelom geulis by providing increased capital to the crafters, bring in investors, and provide marketing opportunities both inside and outside.
\end{abstract}

Key words: kelom geulis art, Tasikmalaya, fashion, woman, marketing

\section{PENDAHULUAN}

Kompleksitas kultural yang ada di Indonesia menjadi cerminan kemajemukan kehidupan masyarakat pendukungnya. Kemajemukan yang ada diperlihatkan dengan adanya keanekaragaman budaya, lingkungan, alam, dan wilayah geografis. Ruyadi (dalam Hindaryati ningsih, 2016: 109), menjelaskan bahwa masyarakat Kampung Benda Kerep Kabupaten Cirebon memiliki pola pewarisan yang berhasil guna dalam mewariskan nilai budaya dan tradisi kepada generasi berikutnya; tradisi dan nilai budaya ada yang berupa tangible dan intangible. Hal yang berupa tangible adalah di antaranya produk kerajinan seperti kelom geulis. Dalam kaitannya dengan keanekaragaman budaya, masyarakat Indonesia telah memperlihatkan adanya keragaman seni tradisional yang tersebar di berbagai daerah, termasuk di dalamnya adalah kerajian tangan tradisional (Gustami, 2007: 31). Keanekaragaman kerajinan ini menjadi satu di antara aset intelektual yang berhubungan dengan sosiokultural yang mesti dilestarikan dan dikembangkan. Sebagai satu aspek di antara tujuh unsur kebudayaan, kesenian tradisional lahir, tumbuh, dan berkembang di tengah-tengah kehidupan masyarakat pendukungnya. Hal ini senada dengan apa yang diungkapkan oleh Susanto (1983: 91) bahwa kesenian merupakan milik bersama dari suatu kelompok sosial dan menjadi cerminan sistem nilainya. Selain itu, perlu dicermati pula keadaan sosial budaya 
yang ada di kawasan nusantara selama dekade terakhir maka pengkajian nilai-nilai budaya daerah secara intensif dan berkesinambungan perlu dilakukan (Purnomowulan, dkk., 2017: 63).

Kerajian tangan tradisional, dalam konteks kajian budaya yang lebih luas, menjadi satu di antara unsur kebudayaan yang bisa dijadikan sebagai subkajian utama. Kajian mengenai kerajinan tangan tradisional dengan seperangkat nilai estetiknya bukanlah sesuatu yang monolitis. Keberadannya sangat berhubungan erat dengan unsur-unsur pokok lainnya, seperti religi, ekonomi, struktur sosial, dan sebagainya. Nilai estetik dalam kerajinan tangan tradisional merupakan fenomena tanda implisit yang berhubungan dengan konstruksi yang lebih besar, yaitu kebudayaan dalam makna yang lebih umum. Hal ini senada dengan apa yang diungkapkan oleh Sumardjo (2006: 43) bahwa nilai estetik seni adalah fenomena sensoris yang mengandung makna implisit.

Sandal kelom geulis Tasikmalaya merupakan sandal lokal yang diproduksi di Tasikmalaya. Kerajinan tangan tradisional ini telah menyimpan nilai historis yang cukup tinggi. Secara historis, jenis sandal ini pada zaman dahulu menjadi satu di antara jenis sandal yang sangat diminati oleh penduduk Tasikmalaya dan sekitarnya. Kerajinan tangan tradisional ini juga merupakan satu di antara jenis kerajinan tangan yang memiliki fungsi dan nilai estetis sekaligus.

Kelom diambil dari bahasa Belanda kelompen yang artinya sandal kayu, kata geulis berasal dari bahasa Sunda yang artinya cantik yang berarti sandal kayu yang cantik. Secara produksi, kelom geulis terbuat dari kayu mahoni atau albasia yang dibuat secara manual dengan menggunakan tangan (Daya Tarik Sandal Kelom Geulis Tasik, http://news.liputan6.com/daya-tarik-sandal-kelomgeulis-tasik). Agar terlihat lebih estetis dan menarik, kelom geulis dilengkapi dengan hiasan yang menggunakan cukilan atau digambar langsung pada bagian kelom. Adapun cara pewarnaannya, digunakan kuas atau dengan airbrush. Penerapan pahatan pada kelom geulis dibentuk dengan garis-garis yang tegas, yang pada umunya berupa motif-motif bunga.

Secara faktual, kelom geulis menjadi satu di antara barang konsumtif yang bisa dimanfaatkan dan dibeli oleh khalayak ramai. Dalam perkembangannya, karena menjadi barang komoditas ekonomi, kelom geulis sangat sensitif terhadap perubahan zaman dan perubahan mode yang sangat ditunjang oleh gaya hidup masyarakat pendukungnya. Dalam hubungannya dengan kondisi demikian, para perajin dituntut untuk bisa memosisikan kelom geulis sebagai komoditas yang siap terus eksis di tengah serbuan komoditas ekonomi lainnya. Oleh karena itu, mereka harus mampu menyeimbangkan kelesuan yang diakibatkan oleh kebosanan konsumen. Tentu, daya kreativitas sangat diperlukan untuk mewujudkan hal demikian.
Umumnya kelom geulis, dalam hubungannya dengan fungsi komoditas, dipakai dan digunakan oleh para wanita, mulai dari remaja hingga orang tua. Pada praktiknya, kelom geulis dimanfaatkan untuk melengkapi busana yang dipakainya sehingga menambah daya tarik estetik bagi pemakainya. Pada posisi inilah, kelom geulis sampai sekarang masih sedikit-banyaknya diminati dan digunakan oleh sebagian besar masyarakat lokal, khususnya masyarakat di tatar pasundan.

Pemilihan warna dan penggunaan motif bunga, dalam hubungannya dengan proses pembuatan, akan sangat berpengaruh terhadap hasil produksi. Kelom geulis yang dilengkapi dengan paduan warna dan motif yang pas akan menghasilkan karya yang memiliki nilai estetik yang sangat tinggi. Pemilihan warna dan penetapan motif pada kelom geulis menjadi elemen terpenting dalam proses produksinya. Biasanya, penetapan motif akan disesuaikan dengan ukuran kaki sehingga motif tersebut mengikuti ukuran kelom yang akan diproduksi. Pemasaran kelom geulis, baik di dalam negeri maupun luar negeri memerlukan lingkungan usaha yang baik, berupa enviromental dan enterpreunership; kedeua hal tersebut mutlak diperlukan dalam memasarkan produksi (Schaper, dalam Sukoco dan Muchyi, 2015: 156).

Dalampenelitianinidikajikelomgeulis Tasikmalaya sebagai pelengkap fashion wanita. Hasil dari penelitian ini diharapakan dapat menjadi sumbangan intelektual untuk rujukan pemerintah daerah dalam mengembangkan potensi wisata budaya, khususnya dalam kerajinan tangan tradisinal kelom geulis Tasikmalaya.

\section{METODE}

Metode penelitian yang digunakan dalam penelitian ini adalah metode deskriptif-analitik, yaitu metode yang digunakan untuk menggambarkan fenomena-fenomena yang ada, yang berlangsung saat ini atau saat yang lampau. Metode kajian yang digunakan pada penelitian ini adalah metode kajian etnografi. Idrus (2009: 59-60) menyatakan bahwa etnografi merupakan satu di antara istilah yang merujuk pada penelitian kualitatif. Etnografi diartikan sebagai usaha mendeskripsikan kebudayaan dan aspekaspeknya dengan mempertimbangkan latar belakang permasalahan secara menyeluruh. Etnografi sebagai bentuk penelitian memiliki beberapa karakteristik, yaitu sebagai berikut:

a. selalu menekankan pada penggalian alamiah fenomena sosial yang khusus;

b. memiliki data yang terstruktur dan rancangan penelitiannya bersifat terbuka;

c. dalam melakukan penelitian, peneliti bertindak sebagai instrumen yang berupaya menggali data yang dibutuhkan terkait dengan fokus penelitian;

d. kasus yang diteliti cenderung sedikit atau bahkan hanya satu kasus yang kemudian dikaji secara mendalam; 
e. analisis data tentang makna dan fungsi perilaku manusia ditafsirkan secara eksplisit dalam bentuk deskripsi dan penjelasan verbal;

f. etnografi tidak menggunakan analisis statistik, tetapi tidak berarti menolak data yang berupa angka-angka.

Dengan menggunakan metode kajian etnografi, dapat diungkapkan fakta kebudayaan masyarakat di Kabupaten Tasikmalaya. Kebudayaan yang dimaksud dalam penelitian ini adalah kesenian tradisional kerajinan kelom geulis secara mendalam. Metode etnografi yang digunakan dalam penelitian ini merujuk pada metode etnografi yang dikemukan oleh Spradley (1997) sebagai analisis maju bertahap. Analisis data dilakukan sejak tahap pengumpulan data dan secara bertahap terus dilakukan hingga akhir peneltian. Akhir penelitian ditentukan sepenuhnya oleh peneliti dengan mengacu kepada metode kajian etnografi (Putra, 2004: 85).

\section{HASIL DAN PEMBAHASAN}

Kabupaten Tasikmalaya merupakan satu di antara kabupaten yang berada di wilayah Priangan Timur Jawa Barat yang masyarakatnya masih menjaga kesenian tradisional yang ada di daerahnya beserta nilai-nilai yang terkandung di dalamnya. Kabupaten Tasikmalaya berbatasan langsung dengan Kabupaten Majalengka dan Kota Tasikmalaya di sebelah utara, Samudera Hindia di sebelah selatan, Kabupaten Ciamis dan Kabupaten Pangandaran di sebelah timur, dan Kabupaten Garut di sebelah barat. Terletak di sebelah tenggara di wilayah Priangan, Kabupaten Tasikmalaya dinilai sebagai kabupaten paling besar dan sangat berperan dalam mengembangkan potensi kesenian yang ada di Priangan Timur (Sumber: http://jabarprov.go.id). Sebagian besar wilayah kabupaten ini merupakan daerah hijau, terutama pertanian dan kehutanan sehingga petani menjadi penduduk mayoritas di kabupaten tersebut. Lokasinya yang berada di bagian Jawa Barat, Kabupaten Tasikmalaya masih menjaga nilainilai kesundaan yang terkandung di dalam bahasa dan budayanya. Satu di antara yang menjadi titik perhatian dari Tasikmalaya adalah kesenian kerajinan. Tingkat kreativitas masyarakat Tasikmalaya yang dinilai cukup tinggi menjadikan kabupaten ini menjadi satu di antara daerah penghasil kerajinan terbesar di wilayah Jawa Barat.

Masyarakat di Kabupaten Tasikmalaya masih menjaga kesenian-kesenian tradisional beserta nilainilai yang terkandung di dalamnya. Kondisi ini secara tidak langsung telah menyebabkan proses regenerasi pengetahuan seputar kesenian di kabupaten ini masih terjaga dengan baik. Adanya regenerasi pengetahuan dari generasi tua ke generasi menjadi faktor penentu eksistensi kesenian di Kabupaten Tasikmalaya. Jika dipetakan, terdapat banyak kesenian yang ada di Kabupaten Tasikmalaya yang tersebar di kecamatan- kecamatan yang ada di kabupaten ini. Kesenian yang paling menonjol dari Tasikmalaya adalah kesenian yang berkaitan dengan kerajinan tangan tradisional. Akan tetapi, pada penelitian ini akan dibatasi hanya pada kesenian yang ikonik di Kabupaten Tasikmalaya, yaitu kerajinan tangan tradisional kelom geulis. Kesenian ini setidaknya akan mewakili eksistensi seni tradisional di Kabupaten Tasikmalaya.

\section{Seni Kerajinan Tangan Tradisional Kelom Geulis}

Secara etimologis, kelom diambil dari bahasa Belanda kelompen yang artinya sandal kayu dan geulis berasal dari bahasa Sunda yang berarti cantik. Kelom geulis berarti sandal kayu yang terlihat cantik. Secara kultural, kelom biasanya dipakai untuk acara-acara tertentu yang sifatnya formal, seperti hajatan, walimahan, dan sebagainya. Kelom geulis biasanya terbuat dari bahan dasar kayu mahoni atau albasia. Masyarakat Kabupaten Tasikmalaya biasanya membuat kelom geulis dengan cara manual. Untuk menambah nilai estetik, kelom geulis biasanya dihias dengan ukiran dengan berbagai motif, seperti bunga. Seiring dengan perkembangannya, sekarang kelom geulis sudah banyak juga yang dihias menggunakan cat airbrush dan hiasan batik atau yang lebih dikenal dengan kelom batik.

Kerajinan kelom geulis banyak diproduksi sebagai industri rumahan di daerah-daerah di Kabupaten Tasikmalaya. Untuk mengembangkan kerajinan ini, dibuatlah sentra kelom geulis Kota Tasikmalaya yang terdapat di Kelurahan Setiamulya, Kelurahan Mulyasari, Kelurahan Kersanegara, Kelurahan Sukahurip, Kelurahan Sumelap, Kelurahan Linggajaya Mangkubumi, dan Kelurahan Gobras. Bagi masyarakat setempat, kerajinan kelom geulis bisa menjadi alternatif sumber penghasilan keluarga.

Kelom khas Tasikmalaya tidak hanya terkenal dalam cakupan nasional, tetapi juga sudah mendunia. Kelom geulis telah diekspor ke wilayah Asia Tenggara, Korea, Jepang, Afrika, Panama, Timur Tengah, dan sebagian wilayah Eropa. Takayal, produksi kerajian kelom geulis ini bisa menjadi satu di antara produk unggulan Indonesia yang mampu bersaing dengan produk mancanegara.

Secara keseluruhan, eksistensi seni kerajinan kelom geulis ini masih terjaga dengan baik. Hal ini disebabkan oleh beberapa faktor, di antaranya adalah adanya proses regenerasi pengetahuan seni yang berjalan dengan baik dari generasi tua ke generasi muda, adanya perhatian dari pemerintah daerah untuk memajukan kerajinan kelom geulis tersebut, dan masih adanya loyalitas dari masyarakat untuk menghargai produk-produk buatan dalam negeri, terlebih yang masih mengandung nilai-nilai tradisional (Yudiman, 2015: 48).

Untuk lebih jelasnya, jenis dan bentuk kerajina kelom geulis di Tasikmalaya dapat dilihat sebagai berikut. 


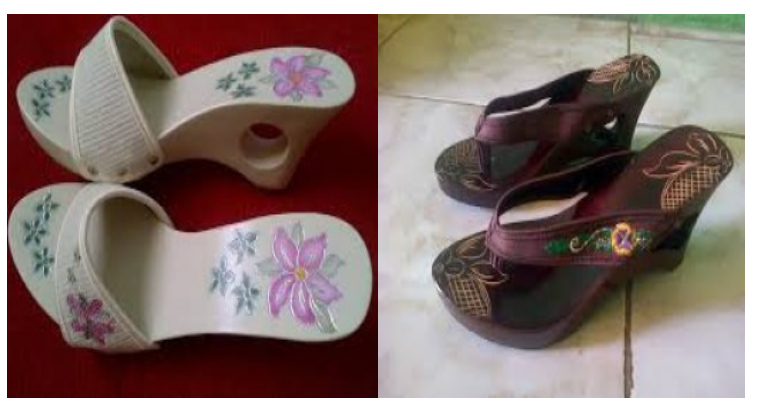

Sumber: http://kerajinanrajapolah.com

Gambar 1. Jenis dan Bentuk Kelom Geulis

Daya tarik kelom geulis terletak pada hiasan yang ada di permukaan sandalnya ataupun di bagian sisi sandalnya. Hiasan kelom geulis mengambil motif bunga seperti bunga mawar, anggrek, melati, kamboja, matahari, bahkan ornamen gambar burung dan karakter tokoh kartun anak-anak juga sering dijadikan hiasan pada sandal kelom geulis. Pada umumnya, pemberian hiasan pada kelom geulis dilakukan dengan teknik cukilan atau digambar langsung pada bagian kelom dengan menggunakan kuas atau dengan airbrush, bahkan ada juga yang dengan menggunakan teknik batik dengan cara mencanting sandal kelom geulis menggunakan bahan lilin malam yang biasa digunakan untuk membatik.

Dalam proses pembuatan kelom geulis, aspekaspek estetis dan ekonomis menjadi pertimbangan yang sangat penting. Untuk lebih jelasnya, berikut aspek-aspek yang perlu diperhatikan dalam membuat kerajinan tangan tradisional kelom geulis.

a. Aspek Fungsi

Ketika membuat dan memproduksi kelom geulis, seorang perajin seharusnya mempertimbangkan terlebih dahulu tujuan dan fungsi produk tersebut dibuat. Aspek ini sangat penting untuk menciptakan produk yang tepat guna dan berkualitas tinggi. Dalam hubungannya dengan nilai estetis, penciptaan motif kelom geulis dengan teknik-teknik tertentu merupakan satu di antara wujud pemenuhan kebutuhan sandang dan kepentingan pelestarian eksistensi estetis kerajinan tangan tradisional, dalam hal ini kelom geulis itu sendiri.

b. Aspek Bahan

Pemanfaatan bahan-bahan tertentu menjadi satu di antara syarat yang perlu dipertimbangkan dalam menciptakan suatu kerajinan tangan tradisional yang bernilai praktis dan berkualitas tinggi. Barang yang diproduksi dengan memanfaatkan bahan baku berkualitas tentu akan menghasilkan produk yang berkualitas juga.

c. Aspek Proses

Untuk menciptakan suatu produk yang berkualitas, perajin tentunya harus mempertimbangkan proses produksi. Pertimbangan kemudahan dan kesulitan dalam membuat produk juga perlu dipertimbangkan sehingga dapat dipertimbangkan kemungkinankemungkinan yang akan terjadi apabila menggunakan peralatan yang seadanya.

\section{d. Aspek Estetis}

Seorang perajin kelom geulis dituntut untuk mampu menjaga nilai-nilai estetis agar tercipta sebuah produk yang bernilai estetis. Hal ini menjadi faktor penentu tingkat ketertarikan konsumen untuk membeli dan menggunakan produknya.

e. Aspek Ergonomis

Aspek ini berhubungan erat dengan pertimbangan keamanan dan kenyamanan dalam pemakaian pruduk. Aspek ini juga penting agar produk tidak hanya memiliki nilai keindahan dan estetis, tetapi juga memiliki tingkat keamanan dan kenyamanan yang cukup tinggi.

f. Aspek Ekonomis

Aspek ini berhubungan dengan jumlah biaya yang dikeluarkan dalam proses produksi dan kemungkinan keuntungan yang akan didapat ketika produk sudah dipasarkan. Kondisi ini dengan sendirinya akan meminimalisasi kemungkinan terjadinya kerugian.

\section{Kelom Geulis sebagai Pelengkap Fashion Wanita}

Seorang wanita dalam berpenampilan perlu mempersiapkan diri dengan berbagai hal. Misalnya, baju, aksesoris, make up, dan sepatu (kelom geulis). Sepatu atau sandal bagi wanita merupakan pelengkap dalam berpenampilan menarik. Oleh karena itu, keberadaan sandal atau sepatu merupakan hal yang sangat penting bagi seorang wanita. Bagian dari sandal atau sepatu dikenal istilah kelom geulis. Untuk masyarakat Jawa Barat, keberadaan kelom geulis memang sudah populer, terutama di kalangan wanita Priangan. Bahkan, dalam acara resepsi (pernikahan, hajatan, reuni, acara ulah tahun), keberadaan kelom geulis bagi kaum wanita tidak dapat dipisahkan dari fashion secara keseluruhan.

Tidak sedikit kaum wanita di Jawa Barat, khususnya di Priangan Timur, kelom geulis dalam acaraacara tertentu merupakan conditio sine quanon kondisi yang harus tetap ada' bagi kaum wanita. Selain fashion, memakai kelom geulis kerap kali dianggap sebagai mode yang trend, karena mereka beranggapan memakai kelom geulis dapat memberikan penampilan yang luar biasa, inspiratif, dan memberikan kepercayaan diri. Selain itu, kaum wanita yang memakai kelom geulis sering dijuluki juga komunitas enéng-enéng geulis (perkumpulan wanita cantik). Kelom geulis berdasarkan penggunanya dibedakan atas kelom geulis untuk komunitas gadis (belum menikah) dan kelom geulis untuk komunitas yang sudah menikah. Hal ini tampak/ dapat dilihat dari bentuk dan warna. Kelom geulis untuk komunitas gadis, memakai kelom yang memiliki hak yang tinggi dan warna relatif cerah, sedangkan kelom geulis untuk kaum ibu memiliki hak yang relatif tidak tinggi atau sedang dan warnanya yang tidak mencolok. Untuk lebih jelasnya dapat dilihat pada gambar-gambar di bawah ini. 


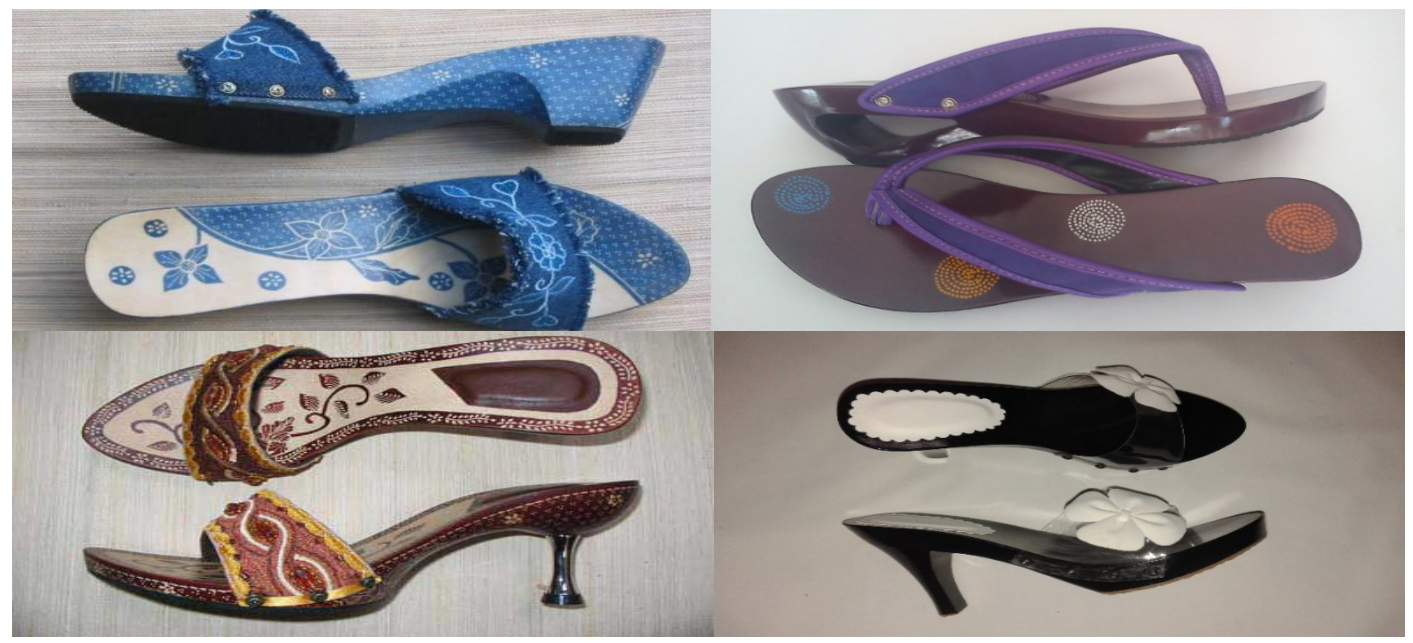

Sumber: https://grosirsandaltasiktermurah.files.wordpress.com

\section{Gambar 2. Variasi Kelom Geulis dari Segi Bentuk dan Warna}

Hasil wawancara (Dedi, perajin Tasikmalaya, 35 tahun) mengungkapkan bahwa wanita di Priangan Timur Jawa Barat pada tahun 1980-an jika pergi ke pesta/resepsi tidak memakai kelom geulis kerap kali mengurungkan/ membatalkan kepergiannya pada acara/resepsi tersebut. Dari fakta tersebbut, jelaslah bahwa keberadaan kelom geulis bagi kaum wanita pada saat itu memang benarbenar sebagai pelengkap fashion dalam berpenampilan menarik. Kini, hal seperti itu tidak kerap ditemukan, tetapi keberadaan kelom geulis untuk melengkapi penampilan kaum wanita selalu menjadi bahan yang sangat dipertimbangkan.

\section{Usaha Pelestarian Kesenian Tradisional Kelom Geulis}

Sebagaisatudiantarakerajinantangantradisional ikonik Kabupaten Tasikmalaya, kelom geulis harus terus dijaga dan dilestarikan. Keberadaannya sebagai aset intelektual yang berhubungan dengan pengetahuan tradisional, kerajinan tangan ini sedikitbanyaknya telah memberikan sumbangsih kultural dalam meningkatkan daya tarik wisata Kabupaten Tasikmalaya, khususnya dalam hal penyediaan souvenir. Akan tetapi, fakta di lapangan terungkap bahwa regenerasi perajin kelom geulis mengalami kendala. Hal ini tampak bahwa generasi penerus (putra-putri dari perajin) tidak/kurang tertarik untuk mengikuti jejak orang tuanya sebagai perajin kelom geulis. Lain halnya dengan pengusaha kelom geulis yang pada umumnya putra-putrinya (generasi penerus) sangat berminat untuk melanjutkan perusahaan orang tuanya.

Oleh karena itu, tim peneliti memberikan rekomendasi untuk kelestarian kelom geulis, yaitu sebagai berikut: (a) adanya pembinaan sedini mungkin (usia SD) memperkenalkan seni leluhur ini kepada generasi penerus, (b) adanya peran pemerintah berupa peningkatan fasilitas (peningkatan kesejahteraan untuk perajin, mendapatkan peluang modal yang mudah, adanya pelatihan dan workshop, dan membantu memasarkan).

\section{SIMPULAN}

Kerajinan tangan tradisional kelom geulis Tasikmalaya merupakan satu di antara kesenian ikonik Tasikmalaya yang sampai sekarang eksistensinya masih terjaga dengan baik. Keterjagaan/keberadaan kerajinan kelom geulis di Tasikmalaya tidak lepas dari kondisi masyarakat Tasikmalaya yang memiliki tradisi (budaya) tinggi dalam menuangkan ide atau gagasan ke dalam bentuk produk nyata (tangible).

Kerajinan tangan tradisional kelom geulis Tasikmalaya memiliki nilai estetik yang mampu dijadikan sebagai pelengkap fashion wanita. Hal ini tampak dari adanya tradisi bahwa setiap acara yang berkaitan dengan pesta pernikahan, ulang tahun, khitanan, dan acara resmi kedinasan eksistensi kelom geulis menjadi pelengkap sebagai aksesoris kaum wanita (termasuk kaum ibu-ibu). Aspek penting yang menunjang kemajuan kerajinan tangan tradisional kelom geulis Tasikmalaya adalah aspek fungsi, aspek bahan, aspek estetis, aspek ergonomis, dan aspek ekonomis.

Rekomendasi untuk kelestarian kelom geulis, yaitu adanya pembinaan sedini mungkin (usia SD) memperkenalkan seni leluhur ini kepada generasi penerus dan adanya peran pemerintah berupa peningkatan fasilitas (peningkatan kesejahteraan untuk perajin, mendapatkan peluang modal yang mudah, adanya pelatihan dan workshop, membentuk sentra kerajinan tangan kelom geulis secara masif dan terpusat, serta membantu memasarkan).

\section{DAFTAR PUSTAKA}

Susanto, A.S. (1983). Pengantar Sosiologi dan Perubahan Sosial. Jakarta: Binacipta.

Gustami, SP. (2007). Butir-butir Mutiara Estetika Timur Ide Dasar Penciptaan Seni Kriya Indonesia. Yogyakarta: Prasista.

Hindaryatiningsih, N. (2016). "Model Proses Pewarisan Nilai-Nilai Budaya Lokal dalam Tradisi Masyarakat Buton”. Sosiohumaniora. Vol. 18 (2): 109. 
Idrus, M. (2009). Metode Penelitian Ilmu Sosial. Yogyakarta: Erlangga.

Purnomowulan, R., Machdalena, S., Dewi, E.R. dan Endrawan, A. (2017). “Teknologi Tepat GunaMembangun Kecintaan dan Kebanggaan pada Kearifan Lokal Bahasa Sunda”. Jurnal Panggung. Vol. 27 (1): 63.

Putra, A.H.S. (2004). Mengembangkan Wisata Budaya dan Budaya Wisata. Jogyakarta: Pusat Studi Pariwisata UGM.

Spradley, J.P. (1997). Metode Etnografi. Yogyakarta: Tiara Wacana.

Sukoco, I. dan Muchyi, H.A. (2015). "Ecopreneuership dalam Menumbuhkan Usaha Berwawasan Lingkungan pada Sentra Industri Penyamakan Kulit Sukaregang Kabupaten Garut”. Sosiohumaniora. Vol. 17 (2): 156.
Sumardjo, J. (2006). Estetika Paradoks. Bandung: STSI

Yudiman, M. (2015). Khazanah Kota Tasikmalaya. Tasikmalaya: Bagian Humas Setda Kota Tasikmalaya.

http://jabarprov.go.id/index.php/potensi_daerah/ detail/133/1 diakses pada tanggal 1 September 2017

https://grosirsandaltasiktermurah.files.wordpress. com/2016/11/kelom-23.jpg? $\mathrm{w}=359 \& \mathrm{~h}=289$ diakses pada tanggal 4 September 2017.

http://kerajinanrajapolah.com/images/Kelom $\% 20$ Geulis\%20SJP01.jpg diakses pada tanggal 5 September 2017. 